\title{
Portal Hypertension Secondary to Benign Prostatic Hyperplasia
}

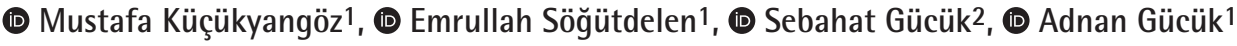 \\ ${ }^{1}$ Bolu Abant izzet Baysal University Faculty of Medicine, Department of Urology, Bolu, Turkiye \\ 2Bolu Abant Izzet Baysal University Faculty of Medicine, Department of Family Medicine, Bolu, Turkiye
}

\begin{abstract}
Benign prostatic hyperplasia (BPH) obstructs the bladder outlet. Patients with BPH frequently present with lower urinary tract symptoms. However, patients with BPH can present with serious fatal complications unless diagnosed and treated sufficiently. In this case report, we present the case of a 63-year-old male patient with renal insufficiency, generalized edema, and portal hypertension due to chronic obstructive uropathy secondary to $\mathrm{BPH}$. To the best of our knowledge, this is the first report to present portal hypertension secondary to BPH as a rare complication.
\end{abstract}

Keywords: Prostate, BPH complications, generalized edema, portal hypertension

\section{Introduction}

Benign prostatic hyperplasia (BPH) is defined as the enlargement of the prostate gland that obstructs the bladder outlet. BPH is an important cause of lower urinary tract symptoms $(1,2)$. Patients with BPH usually present with voiding and storage symptoms $(1,3,4)$. Complications such as recurrent or persistent urinary tract infections, macroscopic or microscopic hematuria, bladder stones, acute or chronic renal failure, incontinence, erectile dysfunction, and electrolyte imbalance are observed. Moreover, patients with chronic obstruction could present with hypertension secondary to hypervolemia $(5,6)$.

Portal hypertension (PH) is defined as an increase in blood pressure between the inferior vena cava and portal veins mainly due to cirrhosis. Furthermore, diseases such as portal vein occlusion, primary biliary cholangitis, alcoholic hepatitis, hepatic vein thrombosis, and chronic right heart failure are possible causes of $\mathrm{PH}(7)$.

Renal insufficiency frequently occurs in chronic obstructive uropathies (8). Chronic kidney insufficiency further triggers right heart insufficiency (9). These diseases can cause PH depending on the volume load (10). In this report, we present the case of a patient with generalized edema, renal insufficiency, and $\mathrm{PH}$ secondary to $\mathrm{BPH}$.

\section{Case Report}

A 63-year-old male patient admitted to the department of urology outpatient clinic of our institution for the swelling of the legs, lower abdomen, and genital area (Figure 1a). The patient had no history of $\mathrm{PH}$ or heart failure previously. After taken an informed consent, $\mathrm{n}$ the physical examination, a diffuse bilateral pedal, scrotal, penile, and lower abdominal edema was observed. In the deep abdominal palpation, we observed a mass effect of the overfilled bladder in the suprapubic region due to urinary retention.

Furthermore, the patient had the following laboratory results: white blood cell, 12,200/uL; hemoglobin, $6.39 \mathrm{~g} / \mathrm{dL}$; blood urea nitrogen, $225 \mathrm{mg} / \mathrm{dL}$; creatinine, $12.45 \mathrm{mg} / \mathrm{dL}$; aspartate aminotransferase, $9 \mathrm{u} / \mathrm{L}$; alanine aminotransferase, $11 \mathrm{u} / \mathrm{L}$; total prostate-specific antigen, $6.66 \mathrm{ng} / \mathrm{mL}$; and free prostate-specific antigen, 1.63 $\mathrm{ng} / \mathrm{mL}$. The patient was consulted with the department of nephrology and was decided not to dialyze since all electrolytes were in the normal range and had no uremic complications.

To further explore renal insufficiency, abdominal ultrasound (US) (GE Healthcare, Chicago, IL, USA) was performed, revealing bilateral grade 3 hydroureteronephrosis with a $74 \mathrm{~mL}$ prostate volume, $37 \mathrm{~mm}$ ureteral stone, and $1.250 \mathrm{~mL}$ residual urine in the bladder. Furthermore, a color Doppler US of the portal system was performed, revealing dilatation of the hepatic veins as well as of the splenic vein and hilum.

Correspondence: Mustafa Küçükyangöz MD, Bolu Abant İzzet Baysal University Faculty of Medicine, Department of Urology, Bolu, Turkiye E-mail: kucukyangoz42@hotmail.com ORCID-ID: orcid.org/0000-0003-4766-7454 Received: 22.05.2021 Accepted: 23.09.2021

Cite this article as: Küçükyangöz M, Söğütdelen E, Gücük S, Gücük A. Portal Hypertension Secondary to Benign Prostatic Hyperplasia.

J Urol Surg, 2022;9(1):74-75.

${ }^{\circ}$ Copyright 2022 by the Association of Urological Surgery / Journal of Urological Surgery published by Galenos Publishing House. 
A 16-French two-way urethral catheter was inserted into the patient to drain residual urine when significant residual urine was observed. The urine output of the patient was $1.500 \mathrm{~mL}$ in 10 min after catheterization. The patient was hospitalized to correct the hemoglobin deficit and monitor renal function. In the control kidney function tests, creatinine level decreased to $5.7 \mathrm{mg} / \mathrm{dL}$ and blood urea nitrogen to $167 \mathrm{mg} / \mathrm{dL}$ by day 5 of admission.

After histopathological confirmation of the prostate by transrectal US-guided biopsy with $\mathrm{BPH}$, an open suprapubic transvesical prostatectomy and cystolithotomy was performed. The patient was discharged on postoperative day 3 with a urethral catheter, which was taken on postoperative day 7 .

Physical examination on postoperative day 7 revealed the complete regression of a generalized edema (Figure 1b). In the control laboratory tests, creatinine was at $4.24 \mathrm{mg} / \mathrm{dL}$ and blood urea nitrogen at $111 \mathrm{mg} / \mathrm{dL}$. Postvoiding residual urine was not observed on US. A control doppler US revealed that PH findings like a dilatation in the splenic and portal veins were completely regressed. The patient was followed up for one year and had normal renal function.

\section{Discussion}

Chronic urinary retention is characterized by the accumulation of urine in the bladder slowly and paimless with volumes ranging between 450 and $4.500 \mathrm{~mL}$. In chronic retention, high pressure in the bladder causes an increase in the pressure of the pelvicalyceal system, leading to bilateral hydronephrosis. Subsequently, this may result in different degrees of renal failure (6).

$\mathrm{PH}$ is asymptomatic until severe complications, such as gastrointestinal bleeding from varices, ascites, and hepatic encephalopathy develop (11). In this study, bilateral grade 3 hydronephrosis, renal insufficiency, generalized edema, and $\mathrm{PH}$ secondary to $\mathrm{BPH}$ were observed. To the best of our knowledge,

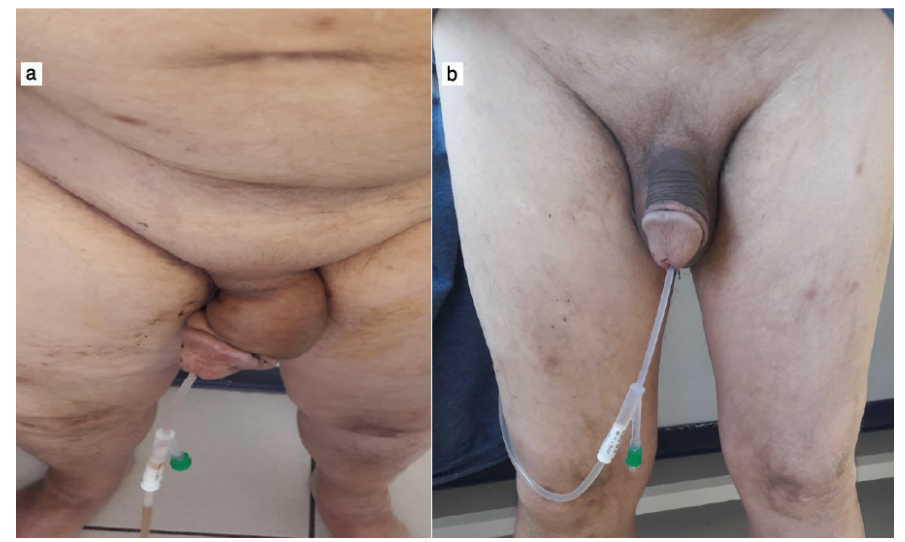

Figure 1. Bilateral lower extremity, penile, and abdominal edema a) at initial admission and b) on postoperative day 7 there was no $\mathrm{PH}$ presentation secondary to $\mathrm{BPH}$. Thus, although a patient may be hospitalized for chronic urinary retention, $\mathrm{PH}$ and its complications should be considered.

\section{Conclusion}

$\mathrm{BPH}$ is the most common cause of obstructive uropathy with rare fatal complications. Its presentation ranges from no symptoms to much more morbid situations like end-stage renal disease, right heart failure, and $\mathrm{PH}$. Thus, if a patient presents with chronic urinary retention and generalized edema, $\mathrm{PH}$ should be checked although it is rare.

\section{Ethics}

Informed Consent: Informed consent was obtained.

Peer-review: Externally peer-reviewed.

\section{Authorship Contributions}

Surgical and Medical Practices: M.K., A.G., Concept: M.K., E.S., Design: M.K., A.G., Data Collection or Processing: M.K., Analysis or Interpretation: E.S., S.G., Literature Search: E.S., S.G., Writing: M.K., E.S.

Conflict of Interest: No conflict of interest was declared by the authors.

Financial Disclosure: The authors declared that this study received no financial support.

\section{References}

1. Egan KB. The Epidemiology of Benign Prostatic Hyperplasia Associated with Lower Urinary Tract Symptoms: Prevalence and Incident Rates. Urol Clin North Am 2016;43:289-297.

2. Vasanwala FF, Wong MYC, Ho HSS, Foo KT. Benign prostatic hyperplasia and male lower urinary symptoms: A guide for family physicians. Asian J Urol 2017:4:181-184.

3. Mobley D, Feibus A, Baum N. Benign prostatic hyperplasia and urinary symptoms: Evaluation and treatment. Postgrad Med 2015;127:301-307.

4. Pearson R, Williams PM. Common questions about the diagnosis and management of benign prostatic hyperplasia. Am Fam Physician 2014;90:769-774.

5. Tseng TY, Stoller ML. Obstructive uropathy. Clin Geriatr Med 2009;25:437-443.

6. Speakman MJ, Cheng X. Management of the complications of BPH/BOO. Indian J Urol 2014;30:208-213.

7. Turco L, Garcia-Tsao G. Portal Hypertension: Pathogenesis and Diagnosis. Clin Liver Dis 2019;23:573-587.

8. McLean RH, Gearhart JP, Jeffs R. Neonatal obstructive uropathy. Pediatr Nephrol 1988;2:48-55.

9. Rangaswami J, McCullough PA. Heart Failure in End-Stage Kidney Disease: Pathophysiology, Diagnosis, and Therapeutic Strategies. Semin Nephrol 2018;38:600-617.

10. Bloom S, Kemp W, Lubel J. Portal hypertension: pathophysiology, diagnosis and management. Intern Med J 2015;45:16-26.

11. Tetangco EP, Silva RG, Lerma EV. Portal hypertension: Etiology, evaluation, and management. Dis Mon 2016;62:411-426. 